\title{
Yozgat Koşullarında Yetiştirilen Yeşil Mercimek Genotiplerinin Verimine Ekim Sıklığının Etkisi
}

\author{
Özge DOĞANAY ERBAŞ KÖSE ${ }^{1}$ Hatice BOZOĞLU ${ }^{2} \quad$ Zeki MUT $^{1}$ \\ ${ }^{1}$ Bozok Üniversitesi, Ziraat Fakültesi, Tarla Bitkileri Bölümü, Yozgat \\ ${ }^{2}$ Ondokuz Mayıs Üniversitesi, Ziraat Fakültesi, Tarla Bitkileri Bölümü, Samsun \\ $\bowtie$ : ozgedoganay.erbas@bozok.edu.tr
}

Geliş (Received): 04.11.2017

Kabul (Accepted): 15.12.2017

\begin{abstract}
ÖZET: Türkiye dünya mercimek üretiminin yaklaşık \% 7'sini karşılamaktadır. Mercimek üretimimizin \% 6.7'sini oluşturan yeşil mercimek, genellikle Orta Anadolu ve Geçit Bölgelerinde yetiştirilmektedir. Yozgat 35.4 bin dekar ile en fazla yeşil mercimek ekimi yapılan ilimizdir. Bu çalışma, Yozgat koşullarında 4 farklı ekim sıklığının (150-225300-375 bitki/m2), 5 tescilli (Sultan 1, Meyveci 2001, Gümrah, Bozok ve Karagül) ve 4 yerel yeşil mercimek çeşidinin verimine etkisini belirlemek için 2 yıl süre ile yürütülmüştür. Deneme bölünmüş parseller deneme deseninde; ana parsellere genotipler, alt parsellere sıklıklar yerleştirilerek üç tekrarlamalı olarak kurulmuştur. Bu makalede, bitki boyu, bin tane ağırlığı, dolu bakla sayısı ve tane verimi özelliklerine ait sonuçlar verilmiştir. Yapılan varyans analizi sonucu incelenen özelliklerin hepsinde genotip, bitkide bakla sayısı ve tane veriminde ise sıklıkların istatistiki etkisi olduğu tespit edilmiştir. En uzun bitki boyu $(41.79 \mathrm{~cm})$ ve bitkide en yüksek bakla sayısı (43.42 adet) Yerel-3, en yüksek 1000 tane ağırlığı (65.7 g) Karagül, en yüksek tane verimi (200.5 kg/da) ise Bozok çeşidinden elde edilmiştir. Tane verimi ve bitkide bakla sayısı, hasat sırasında belirlenen m2'deki bitki sayıları dikkate alınarak regrasyon analizine tabi tutulmuş ve bitki sıklığının tane verimine ikinci dereceden, bakla sayısına ise birinci dereceden önemli $(\mathrm{P}<0.01)$ etkisi olduğu belirlenmiştir. Elde edilen regrasyon denklemi dikkate alınarak tane verimleri hesaplandığında belirlenen bitki sıklıklarında $(91,154,194,252)$ verimin sırasıyla 107.45, 162.90, 186.01, 201.55 kg/da; bitkide bakla sayısının ise 28.97, 24.89, 22.24, 18.41 adet olduğu tespit edilmiştir.

Anahtar kelimeler: Yeşil mercimek, ekim sıklı̆̆
\end{abstract}

\section{The Effect of Plant Density on the Yield of Green Lentil Genotypes Grown in Yozgat Conditions}

ABSTRACT: Turkey provides aproximately $7 \%$ of total production of the world lentil. Green lentil is $6.7 \%$ of the lentil production of Turkey, it is grown in the Central Anatolia and the Transitional Zone. Yozgat has the most sowing area of green lentil with 35.4 thousand decares. This study was carried out for 2 years to determine the effect of 4 different sowing frequency (150-225-300-375 plant/m2), 5 registered (Sultan 1, Meyveci 2001, Gümrah, Bozok ve Karagül) and 4 local lentil varieties in the Yozgat ecological conditions. The experiments set up with a split-plot design in the form of randomized complete blocks with three replications, genotypes took place at main plots and sowing frequency $(150,2225,300,375)$ at sub plots. In this article, plant height, numbers of pods per plant and seed yield characteristics were investigated. Result of analysis of variance, the statistical effects of genotypes were determined for all traits, the number of pods per plant and grain yield were statistically influenced by plant frequencies. Longest plant height $(41.79 \mathrm{~cm})$ Yerel-3; the highest number of pods per plant (43.42) Yerel-3; the most thousand grain weight (65.7 g) Karagül; the highest seed yield (200.5 kg da-1) Bozok variety was obtained. Regression analyses were done for seed yield and number pods per plant. The second-degree polynomial regression were founded the statistically significant $(\mathrm{P}<0.01)$ for seed yield, and only linear effect $(\mathrm{P}<0.01)$ for number of pods plant. When the seed yield was calculated considering the obtained regression equation, the yield and the number of pod per plant was determined $107.45,162.90,186.01,201.55 \mathrm{~kg}$ da-1 and 28.97, 24.89, 22.24, 18.41 no according to sowing frequency of this experiment, respectively.

Key words: Green lentil, plant density, yield, Yozgat

\section{GİRIŞ}

Mercimeğin iri ve orta iri taneli çeşitlerinin doğal gen merkezi olarak kabul edilen ülkemiz, Akdeniz ve Yakın Doğu gen merkezleri üzerinde yer almaktadır (Akdağ, 1996). Dünya'da mercimek ekim alanı 4.5 milyon ha ve üretimi 4.8 milyon ton'dur (FAO, 2014). Dünya mercimek üretiminin yaklaşı $\%$ 7'sini karşılayan ülkemizde mercimek, yemeklik tane baklagiller içerisinde önemli ekim alanına ve üretim miktarına sahiptir. Türkiye mercimek üretiminde Dünya'da
Hindistan ve Kanada'dan sonra üçüncü sırada yer almaktadır (FAO, 2014). Ülkemizde mercimek ekim alanı 252 bin ha ve üretimi 365 bin tondur. Mercimek ekim alanlarımızın sadece 16.7 bin hektarında yeşil mercimek ekilmektedir. Mercimek üretimimizin \% 93.3'ünü oluşturan kırmızı mercimek; kışlık olarak Güneydoğu Anadolu Bölgesinde, \% 6.7'sini oluşturan yeşil mercimek ise yazlık olarak Orta Anadolu ve Geçit Bölgelerinde yetiştirilmektedir. Bazı yeşil mercimek çeşitleri kurağa ve soğuğa dayanaklıdır. Bu 
özelliklerinden dolayı ülkemizin kışı sert geçen bölgelerinde kışlık olarak da yetiştirilebilmektedirler. Ülkemizde yeşil mercimek 40 ilde üretilmekte ve en fazla ekim alanına sahip iller Yozgat, Çorum, Kırıkkale, Ankara, Manisa, Kırşehir ve Konya'dır (TÜİK, 2016).

Mercimek, beslenmeyi engelleyicilerin az, protein oranının yüksek ve pişme süresinin diğer baklagillere oranla kısa olması gibi nedenlerle, insan beslenmesinde diğer yemeklik tane baklagillere göre daha çok tercih edilip kullanılmaktadır (Coşkuner ve Karababa, 1998; Kaya, 2010). Az su tüketmesi, toprağa azot bağlaması ve düşük sıcaklıklara ve kurağa dayanıklılığı nedeniyle yemeklik tane baklagiller içinde yetiştiricilikte ilk sırada yer alan mercimek, tahıllarla münavebeye girmeye uygun ve bunun sonucunda nadas alanlarını azaltmaya elverişli bir bitkidir (Tantekin, 2008). Genetik yap1 ve çevre verimi belirleyici başlıca iki önemli unsurdur. Kaliteli ve bol ürün elde edebilmek için mevcut ekolojik şartlarda en uygun yetiştirme tekniklerinin uygulanması ve verim potansiyeli yüksek çeşitler yetiştirilmesi gereklidir (Bozdemir, 2007). Mercimekte de morfolojik ve fizyolojik özelliklerin önceden belirlenmesi, belli çevre koşullarında genotipler içinden üstün verimli olanları seçmede temel oluşturur. Yerel genotipler o bölgede uzun süre yetiştirildiği için bölgeye uyum sağlamışlardır. Bu sebeple ıslahta ve çeşit geliştirme çalışmalarında önemli kaynaktırlar. Bitki yetiştiriciliğinde birim alan verimliliğini etkileyen en önemli kriterlerden biri bitki sıklığıdır. Çünkü ekimde fazla tohum kullanımı bakım işlerinin etkin yapılamamasına, maliyetin artmasina ve verim kaybına neden olur (Çokkızgın, 2007).

$\mathrm{Bu}$ araştırma, yazlık olarak tescil edilmiş 5 yeşil mercimek çeşidiyle yörede yetiştirilen 4 yerel çeşidin, Yozgat koşullarında verim ve bazı önemli verim unsurlarına farklı bitki sıklıklarının etkilerini belirlemek amacıyla yürütülmüştür.

\section{MATERYAL ve YÖNTEM}

Araştırma, 2014 ve 2015 yıllarında, Bozok Ziraat Fakültesinin Yerköy ilçesindeki uygulama ve araştırma arazisinde 2 yıl süreyle yürütülmüştür. Denemenin yürütüldüğü dönemlere ait iklim verileri Yozgat Meteoroloji Bölge Müdürlüğü'nden alınmıştır. Araştırmanın yapıldığ yetiştirme sezonundaki uzun yıllar yağış toplamı 248.3 $\mathrm{mm}$, sicaklık ortalamas $12.1{ }^{\circ} \mathrm{C}$ ve nispi nem ortalaması \% 63.8 olmuştur. 2014 yilında $353.6 \mathrm{~mm}$ olan yağış toplamı, 2015 yılında 377.3 olmuştur. 2014 ve 2015 yıllarında ortalama aylık sıcaklık değerleri sırasıyla 13.6 ve $12.1{ }^{\circ} \mathrm{C}$ olurken, ortalama nispi nem değerleri 1. yıl \% 55.3 , 2. y1l \% 63.5 olarak tespit edilmiştir. Çalışmanın yürütüldüğü arazi toprağı, $\mathrm{pH}$ bakımından hafif alkali (8.20), orta seviyede kireçli (7.93), hafif tuzlu (0.018), fosfor içeriği orta $(8.62 \mathrm{~kg} / \mathrm{da})$, potasyum içeriği fazla
(48.47 kg/da) ve organik maddesi yetersiz (\% 1.91) olarak belirlenmiştir.

Araştırmada, Tarla Bitkileri Merkez Araştırma Enstitüsünden elde edilen 5 yazlık (Sultan- 1, Meyveci2001, Gümrah, Bozok ve Karagül) ve çiftçiden elde edilen 4 yerel yeşil mercimek çeşidi (Yerel-1, Yerel-2, Yerel-3, Yerel-4) olmak üzere toplam 9 genotip 4 farklı bitki sıklığında (150-225-300-375 adet/ $\mathrm{m}^{2}$ ) denenmiştir. Denemeler bölünmüş parseller deneme deseninde, ana parsellere genotipler, alt parsellere s1klıklar getirilerek 3 tekrarlamalı olarak kurulmuştur. Ekim işlemleri ilk yıl 19.03.2014, ikinci y1l 24.03.2015 tarihlerinde, her parsel 6 sıra olacak şekilde, sıra arası $20 \mathrm{~cm}$ sabit tutularak $4 \mathrm{~m}$ uzunluğundaki sıralara mibzerle yapılmıştır. Hasat, mercimekler sarımsı yeşil rengi aldığ , baklaların 2/3'ü sarardığı zaman parseldeki bitkiler sayılarak elle yapılmıştır. Bitkiler 5-6 gün yı̆̆ınlar halinde tarlada kuruması için bekletilmiş ve harman makinesinde harmanlanmıştır. Denemelerde bitki boyu, bitkide bakla sayısı, bin tane ağırlığı ve dekara tane verimi özelliklerinin tespiti ICARDA tarafından uluslararası baklagil denemelerinde uygulanan yöntemler esas alınarak yapılmıştır (Anonymous, 1985). Elde edilen sonuçlar MSTAT-C istatistik paket programı kullanılarak, yıllar üzerinden birleştirilerek bölünmüş parseller deneme desenine göre analiz edilmiștir. Varyans analiz sonucu sıklık faktörünün önemli olduğu özelliklerde hasat edilen bitki sayıları dikkate alınarak regrasyon analizi yapılmış, elde edilen eşitlikten hareketle planlanan bitki sıklığına ait değerler hesaplanmıştır. Genotipler arasındaki istatistiki farklılıklar Duncan çoklu karşılaştırma testi ile ortaya konulmuştur.

\section{BULGULAR ve TARTIŞMA}

Yozgat koşullarında, 2014-2015 ve 2015-2016 yetiştirme döneminde 9 farklı mercimek genotipinin farklı bitki sıklıklarındaki bitki boyu, bakla sayısı, bin tane ağırlığı ve dekara tane verimi ortalamaları Çizelge 1 'de verilmiştir. Denemenin ilk yılında çiçeklenme dönemi öncesinde parseldeki bitkilerin bir k1smında kuruma tespit edilmiştir. $\mathrm{Bu}$ nedenle planlanan bitki sıklığında değişkenlik olduğu dikkate alınarak hasat sırasında tüm parseldeki bitkiler sayılmış ve $\mathrm{m}^{2}$ 'deki bitki sayısı belirlenmiştir. Bu durumda planlanan bitki sıklıkları 150, 225, 300, 375 adet olmasına rağmen işlem ve tekrarlamalar dikkate alındığında ortalama $\mathrm{m}^{2}$ 'deki bitki sıklığı sırasıyla 91, 154, 194, 252 adet olmuştur. Bu bitki sayıları dikkate alınarak incelenen ve varyans analizi sonucu s1klık faktörünün etkisinin istatistiki olarak önemli olduğu tespit edilen dekara tane verimi ve bitkide bakla sayısı için regrasyon analizi yapılmış ve analiz sonucu tane veriminde ikinci $(\mathrm{P}<0.01)$, bakla sayısında ise birinci dereceden $(\mathrm{P}<0.01)$ etkinin istatistiki olarak önemli olduğu belirlenmiştir (Şekil 1). 
Çizelge 1. Farklı sıklıklarda yazlık olarak ekilen mercimek genotiplerinin iki yıla ait bitki boyu, bakla sayısı, bin tane ağırlığı ve tane verimi ortalamaları

\begin{tabular}{|c|c|c|c|c|c|c|c|c|c|c|c|}
\hline \multirow[b]{2}{*}{ Sıklık } & \multirow[b]{2}{*}{ Yll } & \multicolumn{9}{|c|}{ G E N O T İ P L E R } & \multirow[b]{2}{*}{ Ortalama } \\
\hline & & Sultan & Meyveci & Gümrah & Bozok & Karagül & Yerel-1 & Yerel-2 & Yerel-3 & Yerel-4 & \\
\hline \multicolumn{12}{|c|}{ B İ T K İ B OY U (cm) } \\
\hline \multirow{3}{*}{91} & $1 . Y_{11}$ & 32.0 & 31.1 & 32.6 & 29.8 & 29.8 & 29.6 & 29.0 & 40.5 & 30.8 & 31.7 \\
\hline & 2.Y1l & 36.2 & 37.2 & 34.7 & 33.8 & 34.6 & 39.3 & 32.9 & 36.2 & 33.1 & 35.3 \\
\hline & Ort. & 34.1 & 34.2 & 33.6 & 31.8 & 32.2 & 34.4 & 30.9 & 38.3 & 31.9 & 33.5 \\
\hline \multirow{3}{*}{154} & $1 . Y_{11}$ & 30.5 & 30.3 & 33.8 & 33.7 & 29.3 & 32.1 & 30.1 & 41.9 & 31.8 & 32.6 \\
\hline & 2.Y1l & 33.5 & 34.5 & 35.0 & 37.7 & 35.2 & 34.4 & 33.8 & 42.0 & 31.3 & 35.3 \\
\hline & \begin{tabular}{|l|} 
Ort. \\
\end{tabular} & 32.0 & 32.4 & 34.4 & 35.7 & 32.3 & 33.3 & 32.0 & 42.0 & 31.6 & 34.0 \\
\hline \multirow{3}{*}{194} & $1 . \mathrm{Y} 1$ & 29.7 & 30.8 & 30.6 & 31.3 & 29.4 & 29.9 & 30.0 & 42.7 & 31.1 & 31.7 \\
\hline & 2.Y1l & 33.8 & 32.8 & 37.3 & 37.1 & 36.9 & 35.1 & 32.7 & 41.3 & 34.5 & 35.7 \\
\hline & Ort. & 31.7 & 31.8 & 34.0 & 34.2 & 33.1 & 32.5 & 31.3 & 42.0 & 32.8 & 33.7 \\
\hline \multirow{3}{*}{252} & $1 . Y_{11}$ & 29.4 & 32.6 & 31.9 & 31.3 & 31.0 & 29.6 & 29.7 & 46.0 & 30.9 & 32.5 \\
\hline & 2.Y11 & 35.2 & 31.7 & 39.2 & 33.7 & 35.5 & 32.5 & 36.3 & 43.7 & 36.5 & 36.0 \\
\hline & Ort. & 32.3 & 32.2 & 35.6 & 32.5 & 33.3 & 31.1 & 33.0 & 44.8 & 33.7 & 34.3 \\
\hline \multicolumn{2}{|c|}{ Ortalama } & $32.6 \mathrm{~b}$ & $32.6 \mathrm{~b}$ & $34.4 \mathrm{~b}$ & $33.5 \mathrm{~b}$ & $32.7 b$ & $32.8 \mathrm{~b}$ & $31.8 \mathrm{~b}$ & $41.8 a$ & $32.5 b$ & \\
\hline \multicolumn{12}{|c|}{ B A K L A S A Y I S I (adet) } \\
\hline \multirow{3}{*}{91} & 1.Y1l & 47.5 & 36.8 & 47.4 & 48.1 & 51.6 & 33.8 & 28.9 & 63.3 & 60.1 & 46.4 \\
\hline & $2 . Y_{11}$ & 34.3 & 37.9 & 48.3 & 57.1 & 46.2 & 23.5 & 18.7 & 35.4 & 55.7 & 39.7 \\
\hline & Ort. & 40.9 & 37.3 & 47.9 & 52.6 & 48.9 & 28.7 & 23.8 & 49.4 & 57.9 & $43.0 \mathrm{~A}$ \\
\hline \multirow{3}{*}{154} & 1.Y1l & 26.1 & 38.6 & 31.8 & 43.0 & 45.7 & 30.4 & 28.1 & 51.5 & 46.4 & 38.0 \\
\hline & 2.Y1l & 32.5 & 25.9 & 33.6 & 49.1 & 47.7 & 18.9 & 21.3 & 40.8 & 48.4 & 35.4 \\
\hline & \begin{tabular}{|l|} 
Ort. \\
\end{tabular} & 29.3 & 32.2 & 32.7 & 46.1 & 46.7 & 24.7 & 24.7 & 46.2 & 47.4 & \begin{tabular}{|r|}
$36.7 \mathrm{~B}$ \\
\end{tabular} \\
\hline \multirow{3}{*}{194} & $1 . Y_{11}$ & 28.5 & 28.6 & 34.8 & 31.2 & 33.6 & 29.7 & 36.9 & 47.3 & 27.8 & 33.2 \\
\hline & $2 . Y_{11}$ & 25.2 & 26.3 & 34.2 & 39.3 & 39.1 & 29.0 & 22.2 & 34.8 & 23.3 & 30.4 \\
\hline & Ort. & 26.9 & 27.5 & 34.5 & 35.3 & 36.4 & 29.3 & 29.6 & 41.0 & 25.6 & $31.8 \mathrm{C}$ \\
\hline & 1.Y1l & 28.4 & 24.9 & 28.8 & 22.7 & 24.6 & 22.6 & 35.3 & 43.5 & 26.2 & 28.6 \\
\hline 252 & 2.Y11 & 23.0 & 25.5 & 26.5 & 36.0 & 35.6 & 19.6 & 16.9 & 30.8 & 28.8 & 27.0 \\
\hline & Ort. & 25.7 & 25.2 & 27.7 & 29.4 & 30.1 & 21.1 & 26.1 & 37.2 & 27.5 & $27.8 \mathrm{D}$ \\
\hline Ortala & & $30.7 a b$ & $30.6 a b$ & $35.7 a b$ & $40.8 \mathrm{ab}$ & $40.5 a b$ & $25.9 \mathrm{~b}$ & $26.1 \mathrm{~b}$ & $43.4 a$ & $39.6 a b$ & \\
\hline & & & & B I I N & TANE & A Ğ I R L I & I Ğ I (g) & & & & \\
\hline & 1.Y11 & 64.4 & 68.8 & 63.2 & 57.1 & 68.0 & 59.6 & 65.2 & 51.8 & 56.9 & 61.7 \\
\hline 91 & 2.Y11 & 56.8 & 56.7 & 59.6 & 59.7 & 58.6 & 54.9 & 58.4 & 53.1 & 56.4 & 57.1 \\
\hline & Ort. & 60.6 & 62.7 & 61.4 & 58.4 & 63.3 & 57.2 & 61.8 & 52.5 & 56.6 & 59.4 \\
\hline & 1.Y11 & 64.2 & 60.3 & 62.6 & 62.4 & 69.7 & 59.6 & 58.7 & 53.3 & 54.5 & 60.6 \\
\hline 154 & 2.Y11 & 60.8 & 57.2 & 59.3 & 60.2 & 63.2 & 59.5 & 53.5 & 47.3 & 56.8 & 57.5 \\
\hline & Ort. & 62.5 & 58.7 & 60.9 & 61.3 & 66.5 & 59.5 & 56.1 & 50.3 & 55.6 & 59.0 \\
\hline & 1.Y11 & 63.0 & 63.3 & 60.5 & 67.1 & 75.6 & 59.2 & 57.6 & 54.0 & 56.3 & 61.8 \\
\hline 194 & 2.Y11 & 59.9 & 59.0 & 58.3 & 58.9 & 58.4 & 57.0 & 55.9 & 52.2 & 56.9 & 57.4 \\
\hline & \begin{tabular}{l|l} 
Ort. \\
\end{tabular} & 61.5 & 61.2 & 59.4 & 63.0 & 67.0 & 58.1 & 56.8 & 53.1 & 56.6 & 59.6 \\
\hline & 1.Yil & 60.1 & 63.1 & 60.9 & 67.4 & 68.6 & 56.2 & 59.2 & 53.2 & 54.6 & 60.4 \\
\hline 252 & 2.Y11 & 59.8 & 60.2 & 59.0 & 61.0 & 63.9 & 58.2 & 56.0 & 49.7 & 55.6 & 58.2 \\
\hline & Ort. & 59.9 & 61.7 & 59.9 & 64.2 & 66.2 & 57.2 & 57.6 & 51.5 & 55.1 & 59.3 \\
\hline Ortala & & $61.1 \mathrm{~b}$ & $61.1 \mathrm{~b}$ & $60.4 \mathrm{bc}$ & $61.7 a b$ & $65.7 a$ & $58.0 \mathrm{bc}$ & $58.1 \mathrm{bc}$ & $51.8 d$ & $56.0 \mathrm{~cd}$ & \\
\hline & & & & & NE VE & R İ M İ (k & /da) & & & & \\
\hline & 1.Y11 & 124.3 & 103.5 & 150.4 & 142.0 & 153.5 & 81.7 & 93.8 & 131.7 & 161.1 & 126.9 \\
\hline 91 & 2.Y11 & 80.1 & 72.0 & 150.5 & 115.9 & 101.6 & 75.9 & 76.0 & 79.9 & 76.3 & 92.0 \\
\hline & Ort. & 102.2 & 87.8 & 150.5 & 129.0 & 127.5 & 78.8 & 84.9 & 105.8 & 118.7 & $109.5 \mathrm{C}$ \\
\hline & $1 . Y_{11}$ & 134.9 & 136.7 & 190.3 & 216.7 & 248.3 & 101.6 & 108.3 & 198.4 & 198.8 & 170.4 \\
\hline 154 & 2.Y11 & 129.7 & 148.6 & 169.5 & 161.7 & 146.0 & 94.0 & 98.0 & 133.4 & 119.0 & 133.3 \\
\hline & Ort. & 132.3 & 142.6 & 179.9 & 189.2 & 197.2 & 97.8 & 103.2 & 165.9 & 158.9 & $151.9 \mathrm{~B}$ \\
\hline & 1.Y11 & 218.2 & 213.7 & 246.1 & 252.3 & 327.7 & 202.2 & 133.7 & 269.1 & 197.2 & 228.9 \\
\hline 194 & 2.Y11 & 182.3 & 165.0 & 200.9 & 187.0 & 179.0 & 103.3 & 104.7 & 165.7 & 151.7 & 160.0 \\
\hline & Ort. & 200.3 & 189.3 & 223.5 & 219.7 & 253.3 & 152.8 & 119.2 & 217.4 & 174.4 & $194.4 \mathrm{~A}$ \\
\hline & 1.Y11 & 240.8 & 173.7 & 258.9 & 309.3 & 254.2 & 190.2 & 173.0 & 255.5 & 205.0 & 229.0 \\
\hline 252 & 2.Y11 & 177.3 & 160.0 & 225.7 & 219.4 & 161.3 & 105.0 & 109.0 & 168.4 & 140.0 & 162.9 \\
\hline & Ort. & 209.1 & 166.8 & 242.3 & 264.4 & 207.8 & 147.6 & 141.0 & 212.0 & 172.5 & $195.9 \mathrm{~A}$ \\
\hline Orta & & $160.9 \mathrm{~b}$ & $146.6 \mathrm{bc}$ & $199.0 \mathrm{a}$ & $200.6 a$ & $196.5 a$ & $119.2 \mathrm{~cd}$ & $112.1 \mathrm{~d}$ & $175.3 a b$ & $156.1 \mathrm{~b}$ & \\
\hline
\end{tabular}




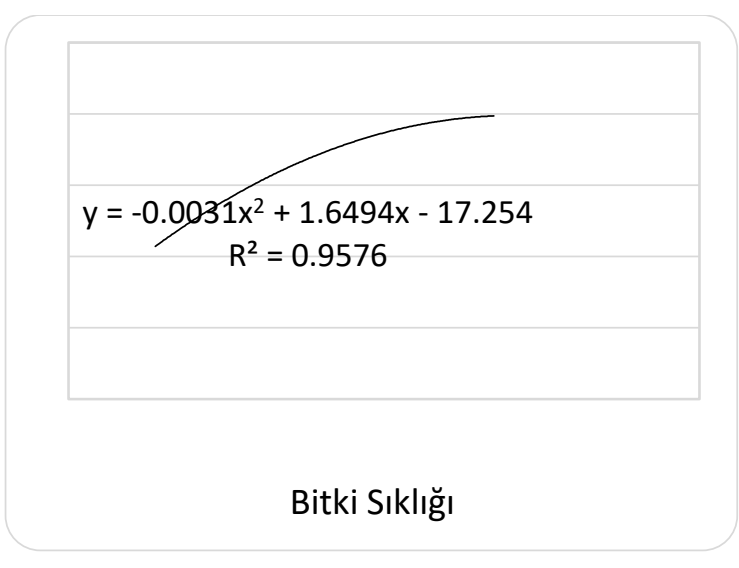

(a)

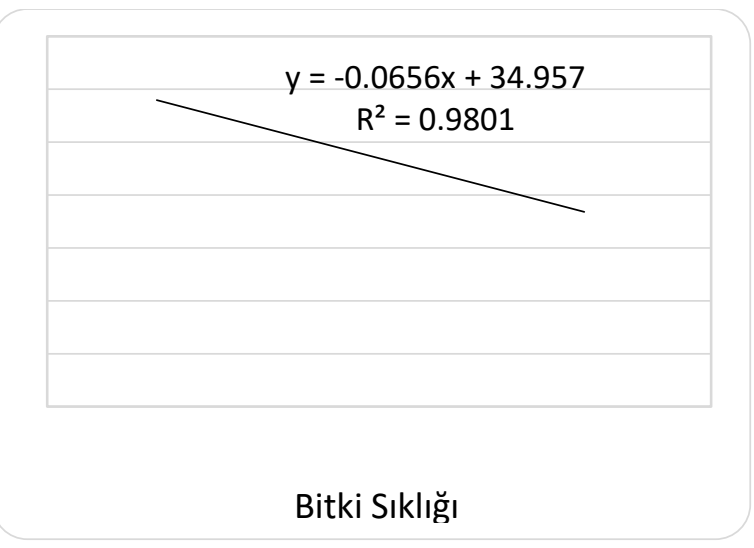

(b)

Şekil 1. Tane verimi (a) ve bakla sayısına (b) ait regrasyon grafiği

Bitki boyu, 32.5 ile $41.8 \mathrm{~cm}$ arasında değişmiş olup, en uzun Yerel-3, en kısa Yerel-4 mercimek genotipinde belirlenmiştir (Çizelge 1). Genotiplerin ortalamasına göre bitki boyu en uzun $34.3 \mathrm{~cm}$ ile 252 bitki sıklığından elde edilmiştir. Yapılan çalışmalarda bitki boyu 37.6 ile $44.4 \mathrm{~cm}$ (Zulkadir ve ark., 2015), 30.0-49.7 cm (Katiyar ve Kant, 2015), 42.0-69.0 cm (Ruisi ve ark., 2015), 29.7 $38.7 \mathrm{~cm}$ (Hussain ve ark., 2014), 14.0-39.4 cm (Toklu ve ark., 2017) arasında değiştiği görülmüştür.

Bitkide bakla sayısı 25.9 ile 43.4 adet arasında değişmiştir. En yüksek bakla sayısı Yerel-3, en düşük ise Yerel-1 mercimek genotipinde görülmüştür. Genotiplerin ortalamasına olarak bakla sayısı en fazla 91 (43.5 adet), en az 252 (27.8 adet) adet bitki sıklığından elde edilmiştir (Çizelge 1). Yapılan çalışmalarda bakla sayısının 22.2-40.7 (Doğan ve ark. 2014), 27.8- 43.3 (Mekonnen ve ark., 2014), 111.6-153.3 (Katiyar ve Kant, 2015), 49.70-60.69 (Zulkadir ve ark., 2015), 10.8-113.6 adet (Toklu ve ark., 2017) arasında değiştiği rapor edilmiștir.

Genotiplerin ortalama bin tane ağırlığ 51.8 ile $65.7 \mathrm{~g}$ arasında değişmiştir. En yüksek bin tane ağırlığı Karagül, en düşük ise Yerel-3 mercimek genotipinden elde edilmiştir. Değişen bitki sıklığında bin tane ağırlığının istatistiksel olarak değişmediği tespit edilmiştir. Yapılan çalışmalarda, bin tane ağırlığını Mekonnen ve ark. (2014) 17-32 g, Katiyar ve Kant, (2015) 11.0-28.5 g, Toklu ve ark. (2017) 12.5-44.0 g arasında değiştiğini bildirmişlerdir.

Farklı s1klıkta ekilen 9 mercimek genotipinde ortalama dekara verim $162.9 \mathrm{~kg}$ olup, verim değerleri 112.0 ile $200.6 \mathrm{~kg} / \mathrm{da}$ arasında değişmiştir. En yüksek verim Bozok çeşidinden elde edilirken, Gümrah, Karagül ve Yerel-3 de aynı istatistik grupta yer almıştır. Yerel-1 ise en düşük tane verimi veren genotip olmuştur. Farklı bitki sıklığında dekara verim 109.5-195.9 kg arasında değişmiş, 194 ile 252 adet $/ \mathrm{m}^{2}$ bitki sıklığ 1 istatistiki olarak aynı sınıfta yer almıştır (Çizelge 1). Dekara verim için tespit edilen regrasyon eşitliği (Şekil-1 a) dikkate alınarak hesaplama yapıldığında, verimlerin 107.45$251.45 \mathrm{~kg}$ arasında değiştiği tespit edilmiştir. Birim alandaki bitki sayısı arttıkça tane verimi artmaktatır. $\mathrm{Bu}$ artış üçüncü doz olan 194 adete kadar istatistiki olarak önemli bulunmuştur. Yapılan çalışmalarda, tane verimini Zulkadir ve ark. (2015) $\mathrm{m}^{2}$ 'de 200 bitki sıklığında 284.38 ve $\mathrm{m}^{2}$ 'de 300 bitki sıklığında $443.75 \mathrm{~kg} / \mathrm{da}$; Ruisi ve ark. (2015) 70-245 kg/da, Mekonnen ve ark. (2014) 64.0$113.2 \mathrm{~kg} / \mathrm{da}$ ve arasında değiştiğini bildirmişlerdir. Bu farklılıkların kullanılan genotipler ve yetiştirme şartlarından kaynaklanabileceği düşünülmektedir.

\section{SONUC}

Ülkemizde yeşil mercimek ile ilgili yeterince bölgesel çalışma bulunmamaktadır. Bu açığı kapamak amacıyla yapılan bu çalışmada değişen iklim ve toprak şartları nedeniyle bitki sıklığı gibi kültürel uygulamaların tespitine yönelik çalışmaların güncelliğini kaybetmesinin söz konusu olmadığı bir kez daha görülmüştür.

Özellikle iklimsel faktörlerdeki değişikliklerin verileri etkilediği tespit edilmiştir. Yerel-3 çeşidi bitki boyu uzun, bakla sayısı fazla olup denemenin en yüksek tane verimi veren ve bölge için önereceğimiz Bozok, Karagül, Gümrah tescilli çeşitleri ile aynı istatistik grupta yer almıştır. Bu sonuçtan hareketle bu yerel çeşidin tesciline yönelik çalışmalarının yapılması gerektiği kanısındayız.

Mercimek gibi sık aralıklarla yetiştirilen bitkilerde sıklık denemelerinde planlanan bitki sayılarının elde edilebilmesi için ekilen tohumların çimlenme yetenekleri önceden mutlak belirlenerek ekilecek tohum miktarının buna göre ayarlanması ve hasatta bitki sayılarının tespit edilerek planlanan rakamlara ulaşılıp ulaşılmadığının belirlenmesi gerekmektedir. Ürün al benisini belirleyen en önemli özelliklerden biri olan bin tane ağırlığının bitki sıklığından etkilenmemiş olması ve tohumluk maliyeti de göz önünde bulundurularak metre karede 194 bitki sıklığının en uygun sıklık olduğu sonucuna varılmıştır.

\section{TEŞEKKÜR}

Bu makale Özge Doğanay ERBAŞ KÖSE 'nin doktora tezinden üretilmiştir. 


\section{KAYNAKLAR}

Akdağ C 1996. Yemeklik Tane Baklagiller. Gaziosmanpaşa Üniversitesi Ziraat Fakültesi Yayınları. Tokat.

Anonymous 1985. Lentil Descriptors. International Board for Plant Genetic Resources (IBPGR) and International Center for Agricultural Research in The Dry Areas (ICARDA), AGPG: IBPGR/85/117. http://www.bioversityinternational.org

Bozdemir Ç 2007. Yazlık Yeşil Mercimek Hatlarının Ankara Ekolojisinde Performanslarının Belirlenmesi. Selçuk Üniversitesi, Fen Bilimleri Enstitüsü, Tarla Bitkileri Anabilim Dalı, Yüksek Lisans Tezi, 98 s.

Coşkuner Y. Karababa E 1998. Türkiye'de Mercimek Üretim Potansiyeli ve İşleme Teknolojisi. Gıda Dergisi, 23 (3): 201-209.

Çokkızgın A 2007. Güney ve Güneydoğu Anadolu Bölgelerinden Toplanan Bazı Kırmızı Mercimek (Lens culinaris medik.) Yerel Genotiplerinin Bitkisel ve Tarımsal Özelliklerinin Belirlenmesi Üzerine Bir Araştırma. Çukurova Üniversitesi, Fen Bilimleri Enstitüsü, Tarla Bitkileri ABD, Doktora Tezi, $127 \mathrm{~s}$.

FAO 2014. Statistical Databases, http://faostat.fao.org/site/567/default.aspx\#ancor, (Mart 2017).

Hussain N, Yaqoob M. Rashid A 2014. Genetic Competition among Lentil (Lens culinaris) Candidate Lines for Yield and Yield Components Under Rainfed Conditions. J. Agric. Res., 52 (1): 53-66.

Katiyar M, Kant R 2015. Multivariate Analysis for Genetic Divergence in Lentil (Lens culinaris Medik). Indian Journal Appled Researche 5 (3): 37-39.

Kaya F 2010. Ülkemizde Yetiştirilen Bazı Mercimek Çeşitlerinin Bileşimlerinin Belirlenmesi. Çukurova
Üniversitesi, Fen Bilimleri Enstitüsü, Gıda Bilimleri Anabilim Dalı, Doktora Tezi, $50 \mathrm{~s}$.

Mekonnen F, Mekbib F, Kumar S, Ahmed S, Sharma TR 2014. Phenotypic Variability and Characteristics of Lentil (Lens culinaris Medik.) Germplasm of Ethiopia by Multivariate Analysis. Journal of Agricultural and Crop Research, 2 (6): 104-116.

Ruisi P, Longo M, Martinelli F, Di Miceli G, Frenda AS, Saia S, Carimi F, Giambalvo D, Amato G 2015. Morpho-Agronomic and Genetic Diversity among Twelve Sicilian Agro-Ecotypes of lentil (Lens culinaris). The Journal of Animal \& Plant Sciences, 25 (3): 716-728.

Tantekin M 2008. Diyarbakır Ekolojik Koşullarında Bazı Kışlık Kırmızı Mercimek (Lens culinaris Medic.) Çeşitlerinde Farklı Ekim Sıklıklarının Verim ve Verim ile İlgili Özelliklere Etkisi Üzerine Bir Araştırma. Çukurova Üniversitesi, Fen Bilimleri Enstitüsü, Tarla Bitkileri Anabilim Dalı, Yüksek Lisans Tezi, $63 \mathrm{~s}$.

TÜİK 2015. Tarımsal İstatistikleri Veri Tabanı. T.C. Başbakanlık Türkiye İstatistik Kurumu, Ankara, www.tuik.gov.tr, (01.05.2017).

Zulkadir G, Çölkesen M, İdikut L, Çokkızgın A, Girgel Ü, Tanrıkulu A, Canbolat M, Güneş M 2015. Kahramanmaraş Koşullarında Farklı Mercimek (Lens culinaris Medic.) Genotiplerinde Bitki Sıklığının Verim ve Verim Unsurlarına Etkisinin Araştırması. Harran Tarım ve Gıda Bilimleri Dergisi, 19 (3): 135 143.

Toklu F, Özkan H, Karaköy T. Coyne CJ 2017. Evaluation of Advanced Lentil Lines for Diversity in Seed Mineral Concentration, Grain Yield and Yield Components. Tarım Bilimleri Dergisi, 23: 213-222. 